\title{
Wind tunnel experiments on dust emissions from different landform types
}

\author{
WU Wei ${ }^{1,2}$, YAN Ping ${ }^{1,2^{*}}$, WANG Yong ${ }^{1,2}$, DONG Miao ${ }^{1,2}$, MENG Xiaonan $^{1,2}$, JI Xinran ${ }^{1,2}$ \\ ${ }^{1}$ Faculty of Geographical Science, Beijing Normal University, Beijing 100875, China; \\ ${ }^{2}$ State Key Laboratory of Earth Surface Processes and Resource Ecology, Beijing Normal University, Beijing 100875, China
}

\begin{abstract}
The measurement and assessment of dust emissions from different landforms are important to understand the atmospheric loading of PM10 (particulate matter $\leq 10 \mu \mathrm{m}$ aerodynamic diameter) and to assess natural sources of dust; however, the methodology and technique for determining the dust still present significant research challenges. In the past, specialized field observation and field wind tunnel studies have been used to understand the dust emission. A series of wind tunnel tests were carried out to identify natural sources of dust and measure the magnitudes of dust emissions from different landforms. The method used in this study allowed the measurement of the PM10 emission rate using a laboratory based environmental boundary layer wind tunnel. Results indicated that PM10 emissions demonstrated strong temporal variation and were primarily driven by aerodynamic entrainment. Sand dunes, playa, and alluvial fans had the largest dust emission rates $\left(0.8-5.4 \mathrm{mg} /\left(\mathrm{m}^{2} \cdot \mathrm{s}\right)\right)$ while sandy gravel, Gobi desert and abandoned lands had the lowest emission rates $\left(0.003-0.126 \mathrm{mg} /\left(\mathrm{m}^{2} \cdot \mathrm{s}\right)\right)$. Dust emissions were heavily dependent on the surface conditions, especially the availability of loose surface dust. High dust emissions were a result of the availability of dustparticle materials for entrainment while low dust emissions were a result of surface crusts and gravel cover. Soil surface property (surface crusts and gravel cover) plays an important role in controlling the availability of dust-sized particles for entrainment. The dust emission rate depended not only on the surface conditions but also on the friction velocity. The emission rate of PM10 varies as a power function of the friction velocity. Although dynamic abrasion processes have a strong influence on the amount of dust entrainment, aerodynamic entrainment may provide an important mechanism for dust emissions. Large volumes of dust entrained by aerodynamic entrainment cannot only occur at low shear velocity without saltation, but may dominate the entrainment process in many arid and semi-arid environments. So it may also be responsible for large magnitude dust storms. Playa and alluvial fan landforms, prior to developing a surface crust, may be the main sources of dust storms in Qinghai Province.
\end{abstract}

Keywords: emission rates; PM10; fugitive dust; landforms; wind tunnel; dust dynamics

Citation: WU Wei, YAN Ping, WANG Yong, DONG Miao, MENG Xiaonan, JI Xinran. 2018. Wind tunnel experiments on dust emissions from different landform types. Journal of Arid Land, 10(4): 548-560. https://doi.org/10.1007/s40333-0180100-4

\section{Introduction}

Dust emissions are widely recognized as an important global environmental problem. Dust not only effects human health and air quality at a local scale (Prospero, 1999; Smith and Lee, 2003; Goudie and Middleton, 2006; Chin et al., 2007), but also contributes to the radiation balance and climate

\footnotetext{
*Corresponding author: YAN Ping (E-mail: yping@bnu.edu.cn)

Received 2017-06-21; revised 2017-11-22; accepted 2017-11-30

(C) Xinjiang Institute of Ecology and Geography, Chinese Academy of Sciences, Science Press and Springer-Verlag GmbH Germany, part of Springer Nature 2018
} 
system at a global scale (Tegen and Lacis, 1996; Harrison et al., 2001; Tegen et al., 2004; Slingo et al., 2006; Neff et al., 2007; Milton et al., 2008; Solomon et al., 2009). In addition, the entrainment, transport, and eventual deposition of dust on the land surface play important roles in nutrient dynamics and biogeochemical cycles (Avila et al., 1998; Leys and McTainsh, 1999; Goudie and Middleton, 2001; Jickells et al., 2005; Mahowald et al., 2010; Lequy et al., 2013), and in the evolution of landform patterns, hydrology, soil properties, and surface landscapes (Swap et al., 1992; Marticorena and Bergametti, 1995; Bryant, 2003; Zender et al., 2003a; Miller et al., 2004; Okin et al., 2004; Tegen et al., 2004; Funk et al., 2008). Consequently, research has focused on understanding the characteristics of dust emissions from landscapes and identifying the natural sources of dust (Xuan et al., 2004; Okin, 2005; Koven and Fung, 2008; Bullard et al., 2011; Sweeney et al., 2011; Tan, 2016). Furthermore, the measurement and assessment of natural dust emissions has become increasingly important for both scientific and practical applications. However, challenges still exist in terms of determining the sources of dust emissions and consequently, the subject remains the focus of considerable investigation.

Arid and semi-arid lands occupy approximately $40 \%$ of the global land area (Biamah, 2005) and are important sources of atmospheric dust loading (Wang et al., 2004; Okin, 2005; Sweeney et al., 2011). These landscapes contain a variety of landforms that have the potential and capacity to emit large volumes of dust. For example, the Gobi desert and alluvial fans adjacent to the Gobi desert are the dominant dust sources in arid and semi-arid regions of China and Mongolia, respectively (Wang et al., 2008). Semi-arid deserts are important dust sources in North America (Hahnenberger and Nicoll, 2014), alluvial sediments and playas have been identified as dust sources in southwestern United States (Reheis et al., 2002), and inland basins have been identified as persistent sources of dust (Washington et al., 2003; Ginoux et al., 2012). Other landforms, such as arid loess-lands, dry river beds, deteriorated grasslands, and barren playas are also regarded as important dust sources (Wang et al., 2004; Eckardt and Kuring, 2005; Goudie and Middleton, 2006; Hahnenberger and Nicoll, 2014). A better understanding of the capacity and potentiality of dust emissions from different landforms will help to assess the influences of dust and to better identify the natural sources of dust. However, an important problem regarding dust emissions is the lack of quantitative measurements (Kohfeld et al., 2005). Previous research employed field based monitoring stations combined with remote sensing and wind tunnel studies to analyze atmospheric dust loading. Recently, portable field wind tunnels and the portable in situ wind erosion laboratory have been used to characterize dust emissions (Etyemezian et al., 2007; Sweeney et al., 2011). A large, portable field wind tunnel is considered as an ideal standard way to measure dust emissions; however, in many cases, a portable wind tunnel is very hard to situate in the field due to the availability, cost, and the requirement for relatively flat topography. This is particularly true for remote areas because it is rarely feasible for such experiments to be conducted. Conversely, simulating and quantifying fugitive dust emission rates by the reproduction of the natural surface in a stationary wind-tunnel are relatively common. The wind tunnel can provide standardized wind conditions and allow for a large number of measurements to be made in a relatively short period of time, which the large portable field wind tunnel cannot do.

Furthermore, the laboratory wind tunnel method allows for the systematic comparison and measurement of the windblown dust emission rate, which could be used in atmospheric dust models. In this study, a laboratory wind tunnel was used to quantify the capacity of dust emissions from different landforms. Eleven types of undisturbed surface soil samples from different landforms of Qinghai Province, China, were used for analysis. Previous studies on dust emissions have utilized different types of sand traps and wind tunnels (Leys and Raupach, 1991; Wiggs et al., 1996; Nickling and Neuman, 1997; Goossens and Offer, 2000; Dong et al., 2004). Dust traps are fixed and can only capture dust-size material (e.g., PM10) but they lack the spatial resolution to capture dust-size material from different landforms. In this study, the atmospheric dust concentration was measured by special instruments which can provide a series of unique and comprehensive data of dust. And this instrument can provide the PM10 data that will help to assess the spatial heterogeneity of dust emissions from different landforms and provide a better understanding of the contribution of different sources to atmospheric dust loading. 


\section{Materials and methods}

\subsection{Study area and sample collection}

Undisturbed soil samples were collected along a transect in northern Qinghai Province, China (Fig. 1) and 11 types of landforms were chosen for analysis (Table 1). We assumed that the heterogeneities of dust emissions on a large scale can also be found from the different types of surfaces by small scale simulations. The main undisturbed surface soil samples were distributed in Gonghe County, Qinghai Lake area, and Golmud, where the landforms are the most typical in Qinghai Province. The distribution of extremely uneven precipitation is influenced by the altitude, monsoon circulation, and topography. The mean annual precipitation is $100-400 \mathrm{~mm}$ in Qinghai Province, with approximately $60 \%$ occurring in summer (May to September). Winds are predominantly northwesterly in winter.

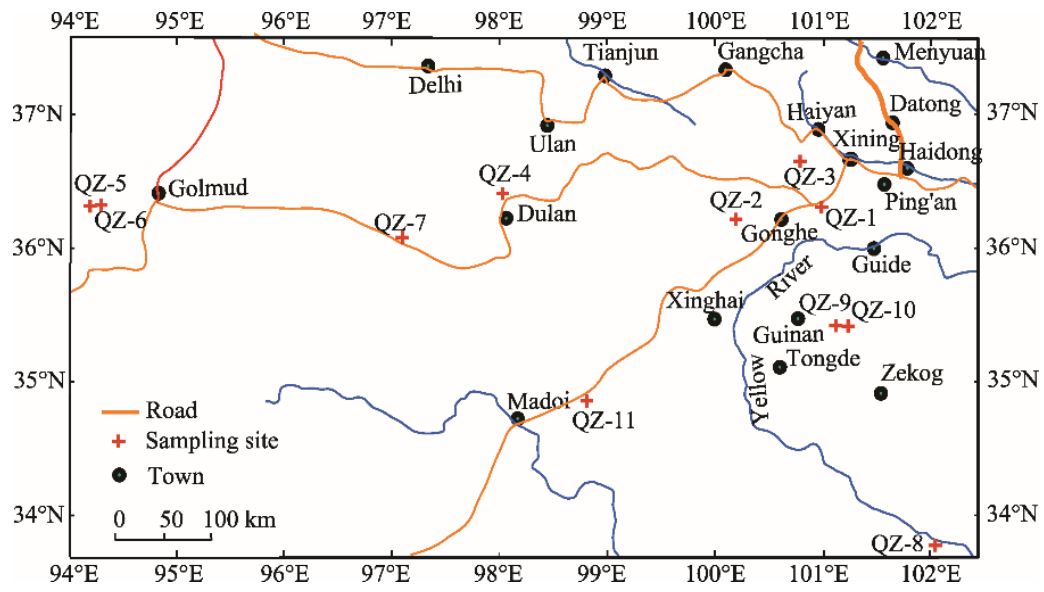

Fig. 1 Locations of sampling sites in Qinghai Province

We collected the soil samples without disturbing its structure. The soil textural characteristics and surface conditions of the samples are presented in Table 1. The methodology for collecting the undisturbed samples is similar to the method described by Zhang et al. (2007) in which they described the steps to collect the soil samples in great detail. Surface soil samples were excavated to a depth of $20 \mathrm{~cm}$, put into the sample boxes (wooden box, $80 \mathrm{~cm} \times 30 \mathrm{~cm} \times 20 \mathrm{~cm}$ ) and transported to the laboratory for further analyses. The boxes were well protected to reduce the contamination

Table 1 Soil texture and surface characteristics

\begin{tabular}{|c|c|c|c|c|c|c|}
\hline \multirow{2}{*}{ Site } & \multicolumn{3}{|c|}{ Component (\%) } & \multicolumn{3}{|c|}{ Surface characteristics } \\
\hline & Sand & Silt & Clay & Setting & Type & Structure \\
\hline QZ-1 & 51.79 & 42.40 & 5.81 & Valley flats & Depositional silt/clay crust & Clay-crusted \\
\hline QZ-2 & 16.96 & 77.73 & 5.31 & Fluvial plain & Depositional silt/clay and occasional relict tire tracks & Clay-crusted \\
\hline QZ-3 & 37.96 & 25.52 & 36.52 & Playa & Depositional silt/clay crust with small swale and extensive & Clay-crusted \\
\hline QZ-4 & 15.20 & 81.30 & 3.50 & Alluvial fans & Depositional silt/clay crust with large polygonal cracking & Clay-crusted \\
\hline QZ-5 & 91.99 & 7.16 & 0.85 & Sand dune & Wind ripples composed of loose sand & Non-cohesive \\
\hline QZ-6 & 90.96 & 8.90 & 0.14 & Sandy gravel & Loose gravel & Non-cohesive \\
\hline QZ-7 & 90.23 & 8.39 & 1.38 & Gobi desert & Coarse pebble lag & Non-cohesive \\
\hline QZ- 8 & 77.59 & 20.07 & 2.34 & Dry river beds & Depositional silt/clay crust & Clay-crusted \\
\hline QZ-9 & 30.51 & 21.40 & 49.09 & Plateau, cultivated land & $\begin{array}{l}\text { Depositional clay crust with large polygonal cracking and } \\
\text { clay surface peels }\end{array}$ & Clay-crusted \\
\hline QZ-10 & 31.15 & 32.81 & 36.04 & $\begin{array}{l}\text { Plateau, abandoned } \\
\text { lands }\end{array}$ & Depositional clay crust with extensive cracking & Clay-crusted \\
\hline QZ-11 & 51.41 & 37.54 & 11.05 & Floodplains & Depositional silt/clay crust & Non-cohesive \\
\hline
\end{tabular}

Note: The soil textural characteristics of each site were as QZ-1, sandy loam; QZ-2, silt loam; QZ-3, clay loam; QZ-4, silt; QZ-5-7, sand; QZ-8, loamy sand; QZ-9, clay; QZ-10, clay loam; QZ-11, loam. 
and damage during the transport. Samples were air-dried to a moisture content of approximately $1.5 \%$. At each sampling location, the surface layer $(0-5 \mathrm{~cm})$ was collected to determine the particle sizes. The particle sizes were analyzed using a Malvern Mastersizer 2000 (Malvern, UK; sample diameter, $0.02-2000 \mu \mathrm{m})$. Soil texture was determined using the percentages of sand $(2.00-0.05$ $\mathrm{mm})$, silt $(0.050-0.002 \mathrm{~mm})$ and clay $(<0.002 \mathrm{~mm})$ by using the United States Department of Agriculture soil texture triangle. The selected sites represent a wide range of soil textural characteristics including: sandy loam (QZ-1), silt loam (QZ-2), clay loam (QZ-3), silt (QZ-4), sand (QZ-5-7), loamy sand (QZ-8), clay (QZ-9), clay loam (QZ-10), and loam (QZ-11). And it can be divided into two general surface structures according to the listed textural groups, there were noncohesive sands, gravels (QZ-5-7 and 11) and depositional clay crusts (QZ-1-4 and 8-10).

\subsection{Wind tunnel}

The wind tunnel experiments were conducted at the State Key Laboratory of Earth Surface Processes and Resource Ecology, Beijing, China. The blow-type, non-circulating wind tunnel has a total length of $34.4 \mathrm{~m}$ with a test section that is $16.0 \mathrm{~m}$ long (Fig. 2), $1.0 \mathrm{~m}$ high and $1.0 \mathrm{~m}$ wide. Wind speed can be controlled continuously from 1 to $40 \mathrm{~m} / \mathrm{s}$. The sample tray was placed in the test section and the surface of the soil sample was kept level with the tunnel floor. Wind speed in the tunnel is measured by a pitot tube that can traverse vertically through the boundary layer. During a typical experiment, the pitot tube starts at a height of $0.01 \mathrm{~m}$ and then traverses upwards to 0.05 , $0.10,0.15,0.20$, and $0.30 \mathrm{~m}$ then stops at the predetermined set point of $0.10 \mathrm{~m}$. These vertical profiles of wind speed are used to obtain the boundary layer profile and the friction velocity $\left(u_{*}\right)$ in the wind tunnel. The friction velocity was calculated using the 'law-of-the-wall' (Eq. 1).

$$
u_{z}=\frac{u_{*}}{k} \ln \left(\frac{z}{z_{0}}\right),
$$

where $u_{z}$ is the wind velocity $(\mathrm{m} / \mathrm{s})$ at the height of $z(\mathrm{~m}), u_{*}$ is friction velocity $(\mathrm{m} / \mathrm{s}), k$ is the von Karman's constant (0.4), and $z_{0}$ is the roughness length $(\mathrm{m})$.

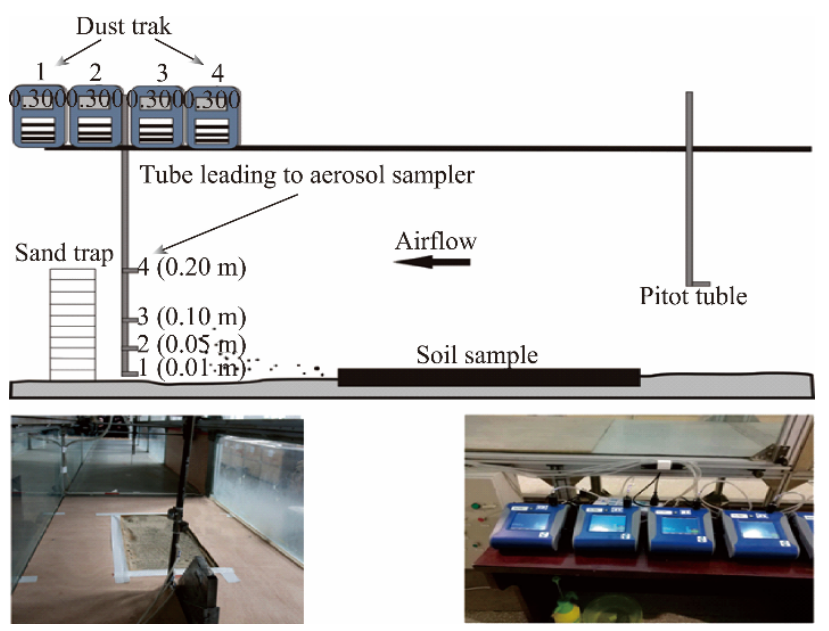

Fig. 2 Schematic of the wind tunnel

During the first stage of the wind tunnel tests for each soil sample, fan speed increased rapidly and was then maintained at a constant for approximately $120 \mathrm{~s}$. The pitot tube was traversed to the set points to obtain the boundary layer profile. For the second stage, the pitot tube was kept at a single height and $z_{0}$ obtained from the first stage was used to solve Equation 1. The duration of each test was $120 \mathrm{~s}$. The concentration of atmospheric dust was measured by Dust-Track II 8530 instrument (DT; Model 8530 produced by TSI in USA), with an operating range of $0.001-150.000$ $\mathrm{mg} / \mathrm{m}^{3}$ and a resolution of $\pm 0.1 \%$. Dust concentrations were measured at 1 -s intervals by four DT instruments located at $0.01,0.05,0.10$, and $0.20 \mathrm{~m}$ above the test surface. Before the wind tunnel 
test, the background concentration of dust was measured. The sediment transport rate was also measured using a step-like slit passive sampler (Chen et al., 1996). A sand trap was placed along the center line of the tunnel in the working section. The sediment transportations at different heights were weighed by an electronic balance $(0.001 \mathrm{~g}$ precision). The method used to calculate the PM10 emission rate is similar to the control volume method described by Roney and White (2006), in which a control volume was defined as $W_{\mathrm{b}} \times L_{\mathrm{b}} \times H_{\mathrm{t}}$. The emissions source area $\left(A_{\mathrm{b}}\right)$ or test surface is determined by its length $L_{\mathrm{b}}$ and width $W_{\mathrm{b}}$, while $H_{\mathrm{t}}$ is the height of the wind tunnel. According to the mass balance of the control volume, the dust emission rate $E\left(\mathrm{~g} /\left(\mathrm{m}^{2} \cdot \mathrm{s}\right)\right)$ was defined as below.

$$
E=\frac{1}{A_{\mathrm{b}}}\left(m_{\mathrm{out}}-m_{\mathrm{in}}\right),
$$

where $m_{\text {in }}$ and $m_{\text {out }}$ are the mass fluxes $(\mathrm{g} / \mathrm{s})$ in and out the control volume, respectively.

The mass flux rates $(\mathrm{g} / \mathrm{s})$ can be determined by the vertical profiles of the dust concentration $(c$ $\left.\left(\mathrm{g} / \mathrm{m}^{3}\right)\right)$ and velocity $(u(\mathrm{~m} / \mathrm{s}))($ Eqs. 3 and 4$)$.

$$
\begin{aligned}
& m_{\text {out }}=\int_{0}^{H_{\mathrm{t}}} c_{\text {out }} \times u \times W_{\mathrm{b}} d z, \\
& m_{\text {in }}=\int_{0}^{H_{\mathrm{t}}} c_{\text {in }} \times u \times W_{\mathrm{b}} d z,
\end{aligned}
$$

where $c_{\text {in }}$ and $c_{\text {out }}$ are the dust concentrations $\left(\mathrm{g} / \mathrm{m}^{3}\right)$ in and out the control volume, respectively.

The emission rate $(E)$ was defined as Equation 5.

$$
E=\frac{1}{L_{\mathrm{b}}} \int_{0}^{H_{\mathrm{t}}}\left(c_{\text {out }} \times u-c_{\text {in }} \times u\right) d z .
$$

We assumes that $c_{\text {in }}=0$ based on the background PM10 concentration in the tunnel. While the sediment collected in the trap was measured, the sand flux $\left(q_{\mathrm{i}}\left(\mathrm{k} /\left(\mathrm{m}^{2} \cdot \mathrm{s}\right)\right)\right)$ can be determined as Equation 6.

$$
q_{i}=\frac{m_{i}}{t \times A_{i}},
$$

where $m_{i}$ is the mass $(\mathrm{g})$ collected in each sand trap at each location, $t$ is the time of collection (s), and $A_{i}$ is the frontal area $\left(\mathrm{m}^{2}\right)$ of the trap. Hence, the total sand flux $\left(Q\left(\mathrm{k} /\left(\mathrm{m}^{2} \cdot \mathrm{s}\right)\right)\right)$ can be determined by Equation 7 .

$$
Q=\sum_{1}^{10}\left(q_{i} \times h_{i}\right)
$$

where $h_{i}$ is the height (m) of each sand trap. This sand flux was an indication of the total horizontal mass (sand together with dust) flux rate for various wind velocities. Once the emission rate of PM10 and the total sand flux rate have been obtained, the ratio $\left(F_{a}\right)$ of vertical flux of PM10 to total horizontal mass flux was calculated using Equation 8.

$$
F_{a}=\frac{E}{Q} .
$$

Macpherson et al. (2008) used the ratio to describe the different soil structural groups. The ratio $\left(F_{a}\right)$ of vertical PM10 flux to total horizontal mass flux was also analyzed in this study.

\section{Results}

\subsection{PM10 concentration profiles}

Detailed profiles of PM10 concentrations were obtained from the wind tunnel tests. Typical data (except for QZ-5, because emissions from this landform are commonly sustained and of a high magnitude) for one experimental run are shown in Figure 3. Time series data shows that there are two stages of dust emissions. At the commencement of the simulation (approximately $5 \mathrm{~s}$ ), dust concentrations exhibited a high-concentration peak then declined rapidly and maintained at lower levels (in some cases close to background concentrations) over time. This peak may suggest a 
limited supply of wind-erodible sediment and that dust emissions depend on the availability of wind-erodible sediment. In other cases, dust concentration peaks are maintained for a few seconds and then slowly decrease. Peaked emissions were typical for clay-crusted surfaces (QZ-1, QZ-3, QZ-4, QZ-9), suggesting that peaked emissions may typically be found in supply limited environments. Sustained dust concentration peaks are found for fine textured soil surfaces and noncohesive sand surfaces (QZ-5, QZ-11). Hence, the dust emission pulse was not driven by saltation bombardment, instead it was driven by aerodynamic entrainment of dust on the surface (Macpherson et al., 2008). Velocity also plays a role in determining dust emission characteristics. As wind speed increases, a second peak in the dust concentration appears. The emission peak caused by increasing wind velocity was typically larger than the initial peak. The time series shown in Figure 3 indicates that the peak emission of PM10 is not only limited by supply of wind-erodible sediment but also the wind velocity.

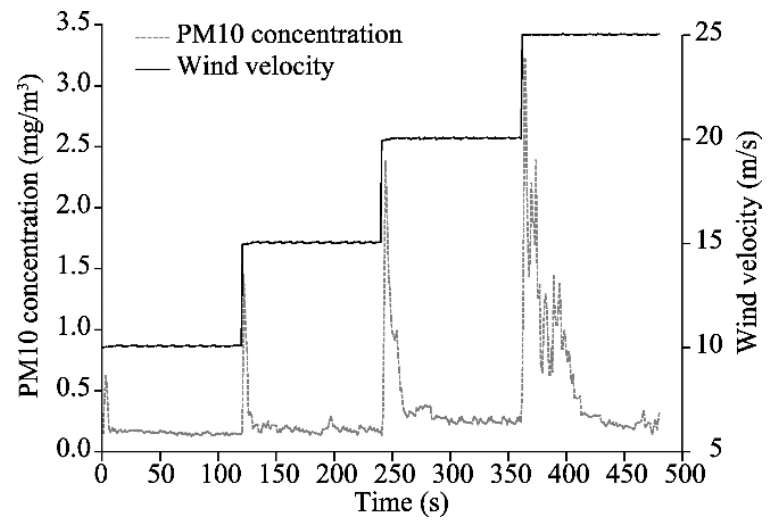

Fig. 3 Representative time series of PM10 concentration emitted from the clay loam surface (QZ-3) at different wind velocities

\subsection{Dust emission rates}

The PM10 dust emission rate was calculated according to Equation 5. It can help to compare the different dust emission rates between different landforms (Fig. 4). The emissions among different landforms varied between 3-5400 $\mu \mathrm{g} /\left(\mathrm{m}^{2} \cdot \mathrm{s}\right)$. Surprisingly, sand dune (QZ-5) was one of the largest dust emitters, despite containing a lower proportion of available silt and clay (average 9\%). Sand dune emissions do not display typical peaks; rather, they maintain a high emission magnitude for the duration of the wind tunnel simulation. Consequently, this landform type emitted significantly more PM10, approximately $800-5400 \mu \mathrm{g} /\left(\mathrm{m}^{2} \cdot \mathrm{s}\right)$, as compared to $3-126 \mu \mathrm{g} /\left(\mathrm{m}^{2} \cdot \mathrm{s}\right)$ for clay-crusted surfaces (QZ-10). Sandy gravel, Gobi desert and the abandoned land with clay crusts have the
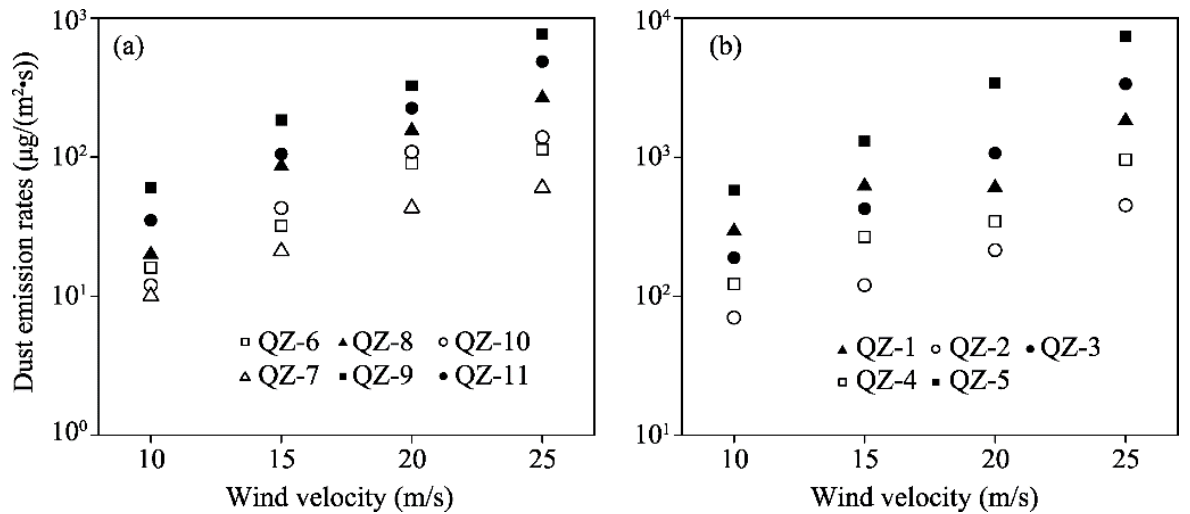

Fig. 4 Dust emissions from individual landforms at different velocities. The soil textural characteristics of each site were as QZ-1, sandy loam; QZ-2, silt loam; QZ-3, clay loam; QZ-4, silt; QZ-5-7, sand; QZ-8, loamy sand; QZ9, clay; QZ-10, clay loam; QZ-11, loam. 
lowest dust emission rates (average $5.0 \mu \mathrm{g} /\left(\mathrm{m}^{2} \cdot \mathrm{s}\right)$ ), suggesting that gravel cover and a surface crust can limit the entrainment of dust from the surface. Sand dune has the highest dust emission rate, which is also uniform; hence, its dust emissions can be characterized as sustained and high magnitude. This may reflect the homogeneous sedimentology of the sand and the influence of saltation. Playa, fluvial plain and alluvial fan were moderate producers of dust. Based on particlesize analysis, these landform types all contain significant amounts of silt and clay (average 76\%). Consequently, it may be easy for them to produce large volumes of dust given sufficient sediment availability. However, there does not appear to be a large emission of dust from these landforms, indicating that surface crusts play an important role in controlling surface dust emissions. The total amount of dust emissions from these landforms can be characterized as high or low, largely dependent on the surface conditions. Surfaces with loose sand or loose sediment presented a great capacity to emit dust whereas surfaces with strong soil crusts or those covered with gravel were low emitters.

The difference in PM10 emission rates depended not only on the surface conditions but also on the friction velocity $\left(u_{*}\right)$. PM10 emission rates increased with friction velocity. Analysis showed that the emission rate of PM10 varies as the cubic function $\left(E=\mathrm{a} \times u_{*}^{3}\right)$ of the friction velocity (Fig. 5; Table 2), and most of their corresponding coefficients of determination $\left(R^{2}\right)$ were good. It showed that the friction velocity has great effect on PM10 emission rates. Surfaces with strong clay crusts or covered with gravel require a higher $u_{*}$ to initiate dust emission, while surfaces with available sand or more sediment availability begin to emit dust at a lower $u_{*}$. As a result, playa, fluvial plain and alluvial fans emit relatively large amounts of dust at lower $u_{*}$, a finding which reflects those of previous studies (Nickling and Gillies, 1993).
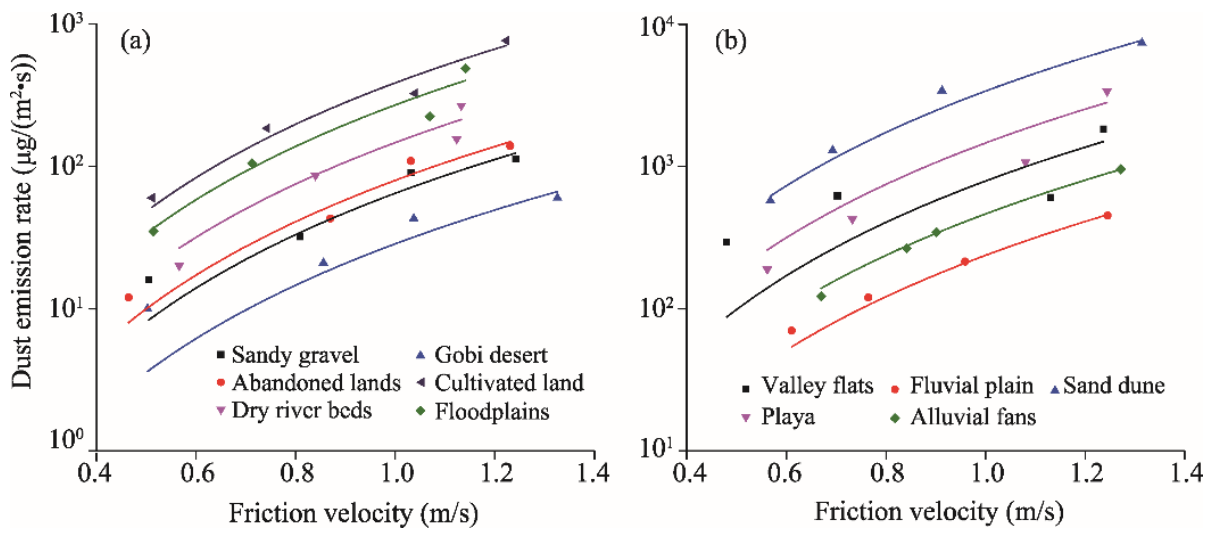

Fig. 5 Relationship between emission rate $(E)$ and friction velocity $\left(u_{*}\right)$

Table 2 Coefficients of dust emission rate $(E)$ and friction velocity $\left(u_{*}\right)$

\begin{tabular}{|c|c|c|c|c|c|}
\hline Surface type & $\mathrm{a}$ & $R^{2}$ & No. & $\mathrm{a}$ & $R^{2}$ \\
\hline Valley flat & 788.32 & 0.59 & Gobi desert & 28.55 & 0.86 \\
\hline Fluvial plain & 236.91 & 0.99 & Dry river beds & 146.73 & 0.83 \\
\hline Playa & 1458.45 & 0.85 & Cultivated land & 384.61 & 0.94 \\
\hline Alluvial fan & 462.90 & 0.99 & Abandoned lands & 79.70 & 0.94 \\
\hline Sand dune & 3376.50 & 0.97 & Floodplains & 269.67 & 0.84 \\
\hline Sandy gravel & 64.61 & 0.92 & & & \\
\hline
\end{tabular}

Note: $E$ and $u_{*}$ have the general form of $E=\mathrm{a} \times u_{*}^{3}$.

\subsection{Vertical flux to total mass flux ratio}

Dust emission models have traditionally focused on the relationship between the emission rate and the friction velocity (Gillette and Passi, 1988; Lu and Shao, 1999; Houser and Nickling, 2001; 
Zender et al., 2003b; Webb and Strong, 2011). $F_{a}$ was a proportion of the total quantity of dust emission and significantly related to the emission rate (Houser and Nickling, 2001). Here, the $F_{a}$ was calculated according to Equation 8. The wind-tunnel results for this ratio can provide comparable data derived using a different method and technique; they can also help to assess the potential dust emission capacity of a landform. Data from the wind tunnel experiment suggest that the value of $F_{a}$ differs between surface types. The value of $F_{a}$ varied between $1.87 \times 10^{-4}$ and $4.39 \times 10^{-3}$, with an average value of $1.26 \times 10^{-3}$ (Fig. 6a). The average value of $F_{a}$ for clay-crusted surfaces was $1.05 \times 10^{-3}$, as compared to $1.63 \times 10^{-3}$ for non-cohesive surfaces. And there was no significant difference in the means between the two groups of surfaces through Paried-Samples $T$ test $(P<0.05)$. But non-cohesive surfaces show a higher value of $F_{a}$ than clay-crusted surfaces. Besides, non-cohesive surfaces display a larger range in value of $F_{a}$ as compared to that of the crusted surfaces, suggesting that the non-cohesive surfaces show a greater degree of variability in $F_{a}$. Comparing the value of $F_{a}$ at different wind velocities showed that the average value of $F_{a}$ was much higher at low velocities as compared to high velocities, especially for clay-crusted surfaces. That is to say, clay-crusted surfaces released more dust per unit $Q$ at low velocities. A curve fitting method based on the least-squares principle is used to analyze the relationship between $F_{a}$ and $u_{*}$. Results show that data are scattered and fail to produce any significant trends with strong correlation coefficients (Fig. 6b). This indicates that there is little relationship between $F_{a}$ and $u_{*}$. And the value of $F_{a}$ cannot be accurately described by a direct relationship with $u_{*}$. Our result is inconsistent with the findings of Alfaro et al. (2004), who found that there was a relationship between $F_{a}$ and $u_{*}$.
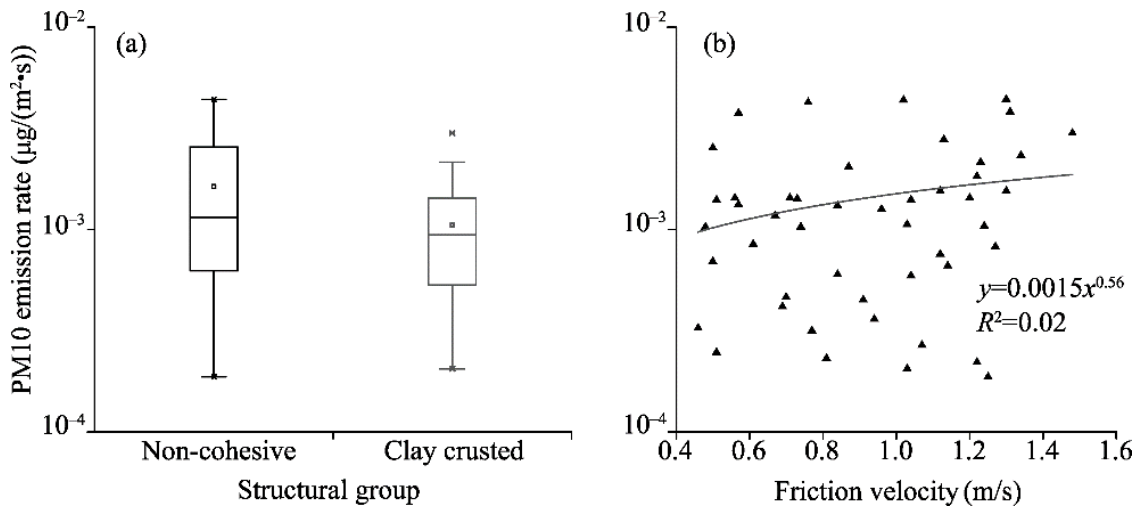

Fig. 6 Box plots of the PM10 emission rates compared with the total sand flux rate associated with each structural group (a) and the relationship between the emission rate and the friction velocity (b)

\section{Discussion}

\subsection{Dust entrainment mechanisms}

One of the main factors affecting dust emissions in the wind tunnel experiments was the limited supply of particles as compared to natural wind erosion events which provide an almost unlimited particle supply. After the entrainable material was depleted, the wind erosion characteristics of the wind tunnel experiments changed rapidly. Another limitation of this experimental design was the inability to reproduce saltating particle, which travel long distances and have a substantial impact on wind erosion characteristics. These factors may have contributed to the peaked dust emissions observed in the wind tunnel experiments. Typical dust emissions in the wind tunnel experiments could be characterized as having two stages. At the onset of the wind, the dust presented a significant high-concentration peak. The availability of dust-sized particles for entrainment was not limited during this stage. However, after the dust-sized particles were depleted, the dust concentration rapidly declined and was maintained at low and stable concentrations over time (close to background dust concentrations in some cases). The availability of dust-sized particles for 
entrainment is the likely reason for this typical dust emission. Comprehensive analysis of our results suggests that aerodynamic uplift is the primary mechanism for dust entrainment. It is widely accepted that dynamic entrainment is one of the most important mechanisms for dust entrainment. However, in the wind tunnel experiments, there was a lack of saltating particles (except for the sand dune sample). In particular, clay-crusted surfaces had no significant saltating particle while the dust concentration remained high. Our results demonstrated that, even very low velocity winds (below the threshold velocity for saltation) entrained very low quantities of dust $\left(243-633 \mu \mathrm{g} /\left(\mathrm{m}^{2} \cdot \mathrm{s}\right)\right)$. This finding is consistent with previous research, suggesting that dust emissions could occur well before the threshold velocity for saltation is reached (Loosmore and Hunt, 2000; Roney and White, 2004). Our observations provide further evidence to suggest that aerodynamic uplift is a potential pathway for dust emissions.

Previous researches indicated that when dust uplift was driven by saltation, dust emissions were proportional to the cube of the friction velocity (Shao et al., 1993). Houser and Nickling (2001) found that a relationship exists between the vertical flux and the emission rate for the abraded surface. They suggested that approximately $55 \%$ of dust was transported vertically $(F=0.55 E)$; hence, a significant relationship between $u_{*}$ and $F_{a}$ should exist if dust uplift is driven by saltation. However, our results showed a weak relationship between $F_{a}$ and $u_{*}$, indicating that $F_{a}$ cannot be described solely by $u_{*}$ (Fig. 6). Therefore, dust uplift is not likely to be driven by saltation in our study. Furthermore, when comparing the values of $F_{a}$ at different velocities (Fig. 6b), some of the average value of $F_{a}$ at low wind speed was even higher than that at the high wind speed. This was particularly true for the clay crust surfaces, where the total horizontal mass flux $(Q)$ was low, but vertical dust flux $(E)$ was relatively high. This result reinforces our finding that a substantial proportion of the dust was due to aerodynamic uplift.

The peak dust emissions that were the typical of our wind tunnel simulations may provide significant information regarding atmospheric dust loadings. Dust emission studies have focused on large-scale emission events, for example dust storms, and dynamic abrasion processes ( $\mathrm{Lu}$ and Shao, 1999; Shao, 2001; Sun et al., 2001; Sassen et al., 2003; Zhang et al., 2008). Although these events can release large amounts of dust into the atmosphere, they occur infrequently as such they may not be the main drivers of high dust concentrations in the field. When the process of aerodynamic entrainment is considered, large volumes of sediments can be entrained at low shear velocity without saltation. Consequently, this process is likely to play an important role in releasing dust into the atmosphere and may be the dominant driver of entrainment in many arid and semiarid environments when the frequency and areal extent of occurrence are considered. Hence, we can conclude that strong wind events are not a necessary prerequisite for dust emissions and high atmospheric dust loading in many cases. Low-magnitude, high-frequency wind events can also contribute to dust emissions through the accumulation of dust over large geographical areas and long periods of time. In recognizing this, dust emission models should consider the aerodynamic entrainment process.

\subsection{Heterogeneity of emissions}

Many dust models attempt to recognize the heterogeneity of dust emissions at a large scale by considering the climate, vegetation cover, hydrology, regional topography, and geomorphology as influencing factors (Zender et al., 2003b; Okin, 2005). Heterogeneity of emissions also can be documented in our wind tunnel study and can primarily be explained as the surface crust, the availability of dust-sized particles for entrainment, and gravel cover. The results of our study indicated that the soil surface samples presented a broad range of dust emission rates; the maximum rate being one to two orders or magnitude larger than the minimum rate for the same wind speed, especially when the surface was crusted (Fig. 4). Hence, surface crusts play an important role in dust emissions. As compared to non-cohesive surfaces, crust surface dust emissions can be maintained at low levels even at high wind velocities. Surfaces with soft crusts (QZ-3, QZ-4) were among the highest dust emitters whereas surfaces with strong soil crusts (QZ-9, QZ-10) were low emitters. Soil texture (grain-size distributions) was not clearly related to dust emission in our wind tunnel tests. For example, the sand dune (QZ-5) contained a very small proportion (less than 9\%) 
of dust-sized material (silt and clay), but had one of the highest dust emission rates. Conversely, the surfaces QZ-9 and QZ-10 contain a high proportion of dust-sized material, but the total amount of dust released from those surfaces was negligible. This discrepancy is related to the surface crust and surface sediment availability. This suggests that the proportion of available dust-sized material may be underestimated in some cases. For example, when comparing the dust emission capacity of different surfaces, we only consider soil texture. However, the dispersion of soil for particle-size analysis can decompose soil aggregates into dust sized particles and may overvalue the dust emission capacity. Consequently, it is the availability of dust-sized material for entrainment rather than the potentially available dust-sized material (soil texture) that determines the capacity for dust emissions. Put simply, soil texture alone does not account for dust emission capacity. In some cases, disturbing the surface may effectively increase the availability of material for dust entrainment by redistributing previously sheltered material which may significantly increase the rate of dust emission. Thus, soil surface properties (surface crusts and gravel cover) play an important role in controlling the availability of the dust-sized particles for entrainment.

Sand dunes demonstrated some of the highest emissions in the wind tunnel tests. However, sand dunes are not considered as a natural hot spot for dust emission (Sweeney et al., 2011). The $F_{a}$ value of sand dune was smaller as compared to other land surfaces; meaning that the proportion of PM10 in the total amount of sand transportation was much lower and the amount of dust released per Q was much lower for the sand dune. And the PM10 was transported vertically, which may suggest that only a small percentage of dust emitted from this surface is transported vertically. Combined with particle size analysis, sand dunes tend to contain a very small proportion of PM 10. So it may release relatively small dust under the same conditions. Beside, according to the structure of sand flux collected from the sand trap, almost $90 \%$ of the total amount of sand transportation was distributed at a height of 0-12 cm (Fig. 7), which means that more of the sand transportation was distributed in near-surface and cannot transport far away. So it may have a little contribution to long-distance dust. Hence, sand dunes may not be the main source of sand-dust storms over a large extent. Alluvial fans and playa had moderate emission rates but the highest
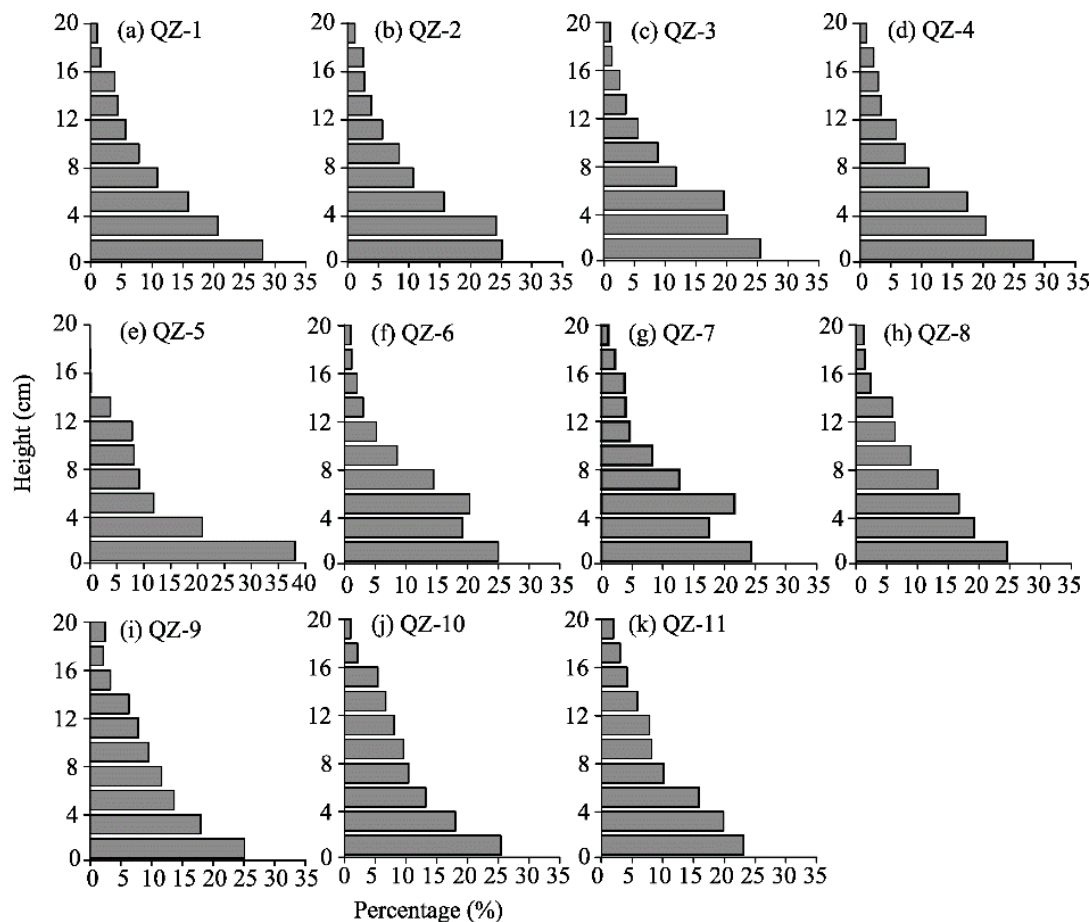

Fig. 7 Relative percentage of sand transportation at different heights in structure of sand flux of different types of surface in the wind tunnel 
values of $F_{\mathrm{a}}$, indicating that alluvial fans and playa release more dust per unit $Q$ as compared to other land surfaces. Playas and fluvial plains contain a very large proportion of dust-sized material (silt and clay), but in many cases the available sediment is limited due to surface crusting. These surfaces have a significant capacity for dust emission if sediment availability was not limited. For example, when these landforms have no vegetative cover and before surface crusts begin to form, these surfaces can release large volumes of dust and become the main sources of atmospheric dust loading. Previous studies have also shown that the alluvial and playa landforms are major regional dust producers (Gill, 1996; Prospero et al., 2002; Reheis, 2006; Katra and Lancaster, 2008; Hahnenberger and Nicoll, 2014) as such we conclude that alluvial fans and playa may be the main sediment sources for large scale sand-dust storms.

\section{Conclusions}

A series of wind tunnel tests were carried out to establish a methodology for determining the dust emission rates from different land surface types and to attempt to identify the main sources of dust. Our results showed that PM10 emissions demonstrated strong temporal variation and were primarily driven by aerodynamic entrainment. Sand dunes, playa, and alluvial fans were the highest dust emitters $\left(0.8-5.4 \mathrm{mg} /\left(\mathrm{m}^{2} \cdot \mathrm{s}\right)\right)$, while sandy gravel, the Gobi desert, and abandoned lands were the lowest dust emitters $\left(0.003-0.126 \mathrm{mg} /\left(\mathrm{m}^{2} \cdot \mathrm{s}\right)\right)$. Dust emissions were heavily dependent on the surface conditions, especially the availability of loose surface dust. Dust emissions were directly influenced by the availability of dust-sized particles and friction velocity. Soil surface properties (surface crusts, gravel cover) play an important role in controlling the availability of dust-sized particles for entrainment. Furthermore, aerodynamic entrainment may provide an important mechanism for dust emissions and may be responsible for large magnitude dust storms in arid and semi-arid environments. Prior to developing a surface crust, playa and alluvial fans are likely to be the main sources of large magnitude dust storms in Qinghai Province.

\section{Acknowledgements}

This study was supported by the National Basic Research Program of China (2016YFA0601901, 2013CB956001).

\section{References}

Alfaro S C, Rajot J L, Nickling W. 2004. Estimation of $\mathrm{PM}_{20}$ emissions by wind erosion: main sources of uncertainties. Geomorphology, 59(1-4): 63-74.

Avila A, Alarcon M, Queralt I. 1998. The chemical composition of dust transported in red rains-its contribution to the biogeochemical cycle of a holm oak forest in Catalonia (Spain). Atmospheric Environment, 32(97): 179-191.

Biamah E K. 2005. Coping with Drought: Options for Soil and Water Management in Semi-Arid Kenya. Wageningen: Wageningen University and Research, 159-164.

Bryant R G. 2003. Monitoring hydrological controls on dust emissions: preliminary observations from Etosha Pan, Namibia. Geographical Journal, 169(2): 131-141.

Bullard J E, Harrison S P, Baddock M C, et al. 2011. Preferential dust sources: A geomorphological classification designed for use in global dust-cycle models. Journal of Geophysical Research: Earth Surface, 116(F4): 4034

Chen W N, Dong Z B, Li Z S, et al. 1996. Wind tunnel test of the influence of moisture on the erodibility of loessial sandy loam soils by wind. Journal of Arid Environments, 34(4): 391-402.

Chin M, Diehl T, Ginoux P, et al. 2007. Intercontinental transport of pollution and dust aerosols: implications for regional air quality. Atmospheric Chemistry and Physics, 7(21): 5501-5517.

Dong Z B, Sun H Y, Zhao A G. 2004. WITSEG sampler: a segmented sand sampler for wind tunnel test. Geomorphology, 59(14): 119-129.

Eckardt F D, Kuring N. 2005. SeaWiFS identifies dust sources in the Namib Desert. International Journal of Remote Sensing, 26(19): 4159-4167.

Etyemezian V, Nikolich G, Ahonen S, et al. 2007. The Portable in Situ Wind Erosion Laboratory (PI-SWERL): A new method to measure $\mathrm{PM}_{10}$ windblown dust properties and potential for emissions. Atmospheric Environment, 41(18): 3789-3796.

Funk R, Reuter H I, Hoffmann C, et al. 2008. Effect of moisture on fine dust emission from tillage operations on agricultural 
soils. Earth Surface Processes and Landforms, 33(12): 1851-1863.

Gill T E. 1996. Eolian sediments generated by anthropogenic disturbance of playas: human impacts on the geomorphic system and geomorphic impacts on the human system. Geomorphology, 17(1-3): 207-228.

Gillette D A, Passi R. 1988. Modeling dust emission caused by wind erosion. Journal of Geophysical Research Atmospheres, 93(D11): 14233-14242.

Ginoux P, Prospero J M, Gill T E, et al. 2012. Global-scale attribution of anthropogenic and natural dust sources and their emission rates based on MODIS Deep Blue aerosol products. Reviews of Geophysics, 50(3): 3005.

Goossens D, Offer Z Y. 2000. Wind tunnel and field calibration of six aeolian dust samplers. Atmospheric Environment, 34(7): 1043-1057.

Goudie A, Middleton N J. 2001. Saharan dust storms: nature and consequences. Earth-Science Reviews, 56(1-4): $179-204$.

Goudie A, Middleton N J. 2006. Desert Dust in the Global System. Berlin Heidelberg: Springer, 156-164.

Hahnenberger M, Nicoll K. 2014. Geomorphic and land cover identification of dust sources in the eastern Great Basin of Utah, U.S.A. Geomorphology, 204: 657-672.

Harrison S P, Kohfeld K E, Roelandt C, et al. 2001. The role of dust in climate changes today, at the last glacial maximum and in the future. Earth-Science Reviews, 54(1-3): 43-80.

Houser C A, Nickling W G. 2001. The emission and vertical flux of particulate matter $<10 \mu \mathrm{m}$ from a disturbed clay-crusted surface. Sedimentology, 48(2): 255-267.

Jickells T D, An Z S, Andersen K K, et al. 2005. Global iron connections between desert dust, ocean biogeochemistry, and climate. Science, 308(5718): 67-71.

Katra I, Lancaster N. 2008. Surface-sediment dynamics in a dust source from spaceborne multispectral thermal infrared data. Remote Sensing of Environment, 112(7): 3212-3221.

Kohfeld K E, Reynolds R L, Pelletier J D, et al. 2005. Linking the scales of observation, process, and modeling of dust emissions. Eos, Transactions American Geophysical Union, 86(11): 113.

Koven C D, Fung I. 2008. Identifying global dust source areas using high-resolution land surface form. Journal of Geophysical Research: Atmospheres, 113(D22): 1971-1976.

Lequy E, Legout A, Conil S, et al. 2013. Aeolian dust deposition rates in Northern French forests and inputs to their biogeochemical cycles. Atmospheric Environment, 80: 281-289.

Leys J F, Raupach M R. 1991. Soil flux measurements using a portable wind erosion tunnel. Australian Journal of Soil Research, 29(4): 533-552.

Leys J F, McTainsh G H. 1999. Dust and nutrient deposition to riverine environments of south-eastern Australia. Sairaanhoitaja, 46: 59-76.

Loosmore G A, Hunt J R. 2000. Dust resuspension without saltation. Journal of Geophysical Research: Atmospheres, 105(D16): 20663-20671.

Lu H, Shao Y P. 1999. A new model for dust emission by saltation bombardment. Journal of Geophysical Research: Atmospheres, 104(D14): 16827-16842.

Macpherson T, Nickling W G, Gillies J A, et al. 2008. Dust emissions from undisturbed and disturbed supply-limited desert surfaces. Journal of Geophysical Research: Earth Surface, 113(F2): 205-208.

Mahowald N M, Kloster S, Engelstaedter S, et al. 2010. Observed 20th century desert dust variability: impact on climate and biogeochemistry. Atmospheric Chemistry and Physics, 10(22): 10875-10893.

Marticorena B, Bergametti G. 1995. Modeling the atmospheric dust cycle: 1. Design of a soil-derived dust emission scheme. Journal of Geophysical Research: Atmospheres, 100(D8): 16415-16430.

Miller R L, Tegen I, Perlwitz J. 2004. Surface radiative forcing by soil dust aerosols and the hydrologic cycle. Journal of Geophysical Research: Atmospheres, 109(D4): 361-375.

Milton S F, Greed G, Brooks M E, et al. 2008. Modeled and observed atmospheric radiation balance during the West African dry season: Role of mineral dust, biomass burning aerosol, and surface albedo. Journal of Geophysical Research Atmospheres, 113(D23): 3614.

Neff J C, Reynolds R L, Farmer G L, et al. 2007. The changing role of dust in biogeochemical cycling. In: AGU Fall Meeting Abstracts. Washington: AGU. V13F-01

Nickling W G, Gillies J A. 1993. Dust emission and transport in Mali, West Africa. Sedimentology, 40(5): 859-868.

Nickling W G, Neuman C M. 1997. Wind tunnel evaluation of a wedge-shaped aeolian sediment trap. Geomorphology, 18(3-4): 333-335.

Okin G S, Mahowald N, Chadwick O A, et al. 2004. Impact of desert dust on the biogeochemistry of phosphorus in terrestrial ecosystems. Global Biogeochemical Cycles, 18(2): 649-655.

Okin G S. 2005. Dependence of wind erosion and dust emission on surface heterogeneity: Stochastic modeling. Journal of Geophysical Research Atmospheres, 110(D11): 1371-1380. 
Prospero J M. 1999. Long-term measurements of the transport of African mineral dust to the southeastern United States: Implications for regional air quality. Journal of Geophysical Research: Atmospheres, 104(D13): 15917-15927.

Prospero J M, Ginoux P, Torres O, et al. 2002. Environmental characterization of global, sources of atmospheric soil dust, identified with the nimbus 7 total ozone, mapping spectrometer, (toms) absorbing aerosol product. Reviews of Geophysics, 40(1), 2011-2024.

Reheis M C, Budahn J R, Lamothe P J. 2002. Geochemical evidence for diversity of dust sources in the southwestern United States. Geochimica et Cosmochimica Acta, 66(9): 1569-1587.

Reheis M C. 2006. A 16-year record of aeolian dust in Southern Nevada and California, USA: Controls on dust generation and accumulation. Journal of Arid Environments, 67(3): 487-520.

Roney J A, White B R. 2004. Definition and measurement of dust Aeolian thresholds. Journal of Geophysical Research Earth Surface, 109(F1): 165-282.

Roney J A, White B R. 2006. Estimating fugitive dust emission rates using an environmental boundary layer wind tunnel. Atmospheric Environment, 40(40): 7668-7685.

Sassen K, DeMott P J, Prospero J M, et al. 2003. Saharan dust storms and indirect aerosol effects on clouds: CRYSTAL-FACE results. Geophysical Research Letters, 30(12): 276-286.

Shao Y, Raupach M R, Findlater P A. 1993. Effect of saltation bombardment on the entrainment of dust by wind. Journal of Geophysical Research: Atmospheres, 98(D7): 12719-12726.

Shao Y P. 2001. A model for mineral dust emission. Journal of Geophysical Research: Atmospheres, 106(D17): 20239-20254.

Slingo A, Ackerman T P, Allan R P, et al. 2006. Observations of the impact of a major Saharan dust storm on the atmospheric radiation balance. Geophysical Research Letters, 33(24): 409-421.

Smith J L, Lee K. 2003. Soil as a source of dust and implications for human health. Advances in Agronomy, 80: 1-32.

Solomon S, Plattner G K, Knutti R, et al. 2009. Irreversible climate change due to carbon dioxide emissions. Proceedings of the National Academy of Sciences of the United States of America, 106(6): 1704-1709.

Sun J M, Zhang M Y, Liu T S. 2001. Spatial and temporal characteristics of dust storms in China and its surrounding regions, 1960-1999: Relations to source area and climate. Journal of Geophysical Research Atmospheres, 106(D10): 10325-10333.

Swap R, Garstang M, Greco S, et al. 1992. Saharan dust in the Amazon Basin. Tellus B, 44(2): 133-149.

Sweeney M R, McDonald E V, Etyemezian V. 2011. Quantifying dust emissions from desert landforms, eastern Mojave Desert, USA. Geomorphology, 135(1-2): 21-34.

Tan M H. 2016. Exploring the relationship between vegetation and dust-storm intensity (DSI) in China. Journal of Geographical Sciences, 26(4): 387-396.

Tegen I, Lacis A A. 1996. Modeling of particle size distribution and its influence on the radiative properties of mineral dust aerosol. Journal of Geophysical Research: Atmospheres, 101(D14): 19237-19244.

Tegen I, Werner M, Harrison S P, et al. 2004. Relative importance of climate and land use in determining present and future global soil dust emission. Geophysical Research Letters, 31(5): 19-105.

Wang X M, Dong Z B, Zhang J W, et al. 2004. Modern dust storms in China: an overview. Journal of Arid Environments, 58(4): $559-574$.

Wang X M, Xia D S, Wang T, et al. 2008. Dust sources in arid and semiarid China and southern Mongolia: impacts of geomorphological setting and surface materials. Geomorphology, 97(3-4): 583-600.

Washington R, Todd M, Middleton N J, et al. 2003. Dust-storm source areas determined by the total ozone monitoring spectrometer and surface observations. Annals of the Association of American Geographers, 93(2): 297-313.

Webb N P, Strong C L. 2011. Soil erodibility dynamics and its representation for wind erosion and dust emission models. Aeolian Research, 3(2): 165-179.

Wiggs G F S, Livingstone I, Warren A. 1996. The role of streamline curvature in sand dune dynamics: evidence from field and wind tunnel measurements. Geomorphology, 17(1-3): 29-46.

Xuan J, Sokolik I N, Hao J F, et al. 2004. Identification and characterization of sources of atmospheric mineral dust in East Asia. Atmospheric Environment, 38(36): 6239-6252.

Zender C S, Newman D, Torres O, 2003a. Spatial heterogeneity in aeolian erodibility: Uniform, topographic, geomorphic, and hydrologic hypotheses. Journal of Geophysical Research, 108(D17): 4543.

Zender C S, Bian H, Newman D. 2003b. Mineral Dust Entrainment and Deposition (DEAD) model: Description and 1990s dust climatology. Journal of Geophysical Research, 108(D14): 269-282.

Zhang B L, Tsunekawa A, Tsubo M. 2008. Contributions of sandy lands and stony deserts to long-distance dust emission in China and Mongolia during 2000-2006. Global and Planetary Change, 60(3-4): 487-504.

Zhang C L, Zou X Y, Yang P, et al. 2007. Wind tunnel test and ${ }^{137}$ Cs tracing study on wind erosion of several soils in Tibet. Soil and Tillage Research, 94(2): 269-282. 